\title{
Research on the Impact of E-commerce Platform Group Buying Situational Characteristics on Consumer Purchase*
}

\author{
Jinjing Li \\ Commercial College \\ Sichuan Agricultural University \\ Dujiangyan, China
}

\author{
Yixi Li \\ Commercial College \\ Sichuan Agricultural University \\ Dujiangyan, China
}

\author{
Chunmei Chen** \\ Commercial College \\ Sichuan Agricultural University \\ Dujiangyan, China \\ **Corresponding Author
}

\begin{abstract}
Objective: To explore the influence of the scenecharacteristics (group purchase duration, discount rate, desire to buy) on the purchase of e-commerce platforms, and provide corresponding guidance for group-merchandising marketing on the e-commerce platform. [Methods] Based on the 35402 pieces of data purchased by a well-known large-scale shopping platform in China, a preliminary analysis of the relationship between variables was conducted using the complex network analysis software GEPHI, and a linear regression model was combined with the customer perceived value theory to verify the discount rate, duration of group purchase, and desire. The effect of the number of purchases on consumer purchases. Conclusion: The study found that: The discount rate, the number of people wanting to buy, and the time of group purchase will have a significant impact on consumers' purchases. Therefore, e-commerce platform merchants should pay attention to this kind of information as much as possible to attract consumers' purchases.
\end{abstract}

Keywords-group purchase time; discount; number of people wanting to buy; GEPHI; regression analysis

\section{INTRODUCTION}

In recent years, the e-commerce platform e-commerce model has risen rapidly in China and even in the global market. According to China E-Commerce Research Center released "2016 (China) E-commerce Market Data Monitoring Report", China's e-commerce transaction volume reached 10.5 trillion Yuan in the first half of 2016, an increase of $37.6 \%$ year-on-year, and the online retail market transaction volume was RMB 2.3 trillion Yuan, a year-on-year increase of $43.4 \%$ [1]. As a new model for the

*The research center for Sichuan liquor industry development in Sichuan University of Science\& Engineering -- the research results of the formation mechanism and cultivation path of marketing dynamic ability of Sichuan wine enterprises (number: CJY17-04) operation of e-commerce platforms, online shopping has developed rapidly. According to the China Internet Network Information Center (CNNIC) released in Beijing the 41st Statistical Report on China's Internet Development, the number of users in China's group purchases maintained a relatively high growth rate [2]. Under the background of fierce competition in group purchase, research on the influencing factors of consumer group purchase behavior can provide important reference for group purchase websites to launch timely, affordable, and appropriate group purchase products. At present relevant scholars have also explored this.

Krishnan S. Anand once suggested that online group purchase refers to the collection of consumers with the same needs via the Internet, relying on collective power to obtain more convenience than individuals, and exerting group effects [3]. In the study of online behaviors, some scholars have studied the characteristics of group-buying commodities, and S Huang has studied the influence of such factors as the price of goods or services on young people's group purchase [4]. Some scholars have also conducted research on group purchase website design. Shiau WL believes that the website design has a significant positive effect on online group purchase intentions [5]. In order to further explore the key factors affecting consumer purchases in group purchase, some scholars focused on certain factors. Erdoğmus IE believes that online group purchase is a system that provides daily discounts for various services and products. The customer's decision is mainly based on price advantage and discount amount [6]. Some scholars have also comprehensively analyzed the influencing factors of consumer group purchase behavior. YF Chen explored the factors that influence consumers' purchases from social, psychological, and personal factors, and concluded that social influence and herd mentality are positively related to online group purchase intentions [7]. 
Reviewing the literature found that scholars mostly study online shopping behaviors in terms of subject factor characteristics or consumer characteristics, commodity characteristics that belong to object factors, and certain key or comprehensive features, but they have a contextual feature under group purchase. The study is slightly less than adequate. However, under the specific time-constrained scenario of group purchase, website design is only an auxiliary method. The characteristics of a product do not change with the situation. The consumer's behavioral attitude is that the business cannot be directly controlled within a certain period of time. In order to study the influencing factors of consumers' purchase intention under specific scenarios, the research on consumer network group purchase from the perspective of the scene features of group purchase itself has an important guiding significance for e-commerce platform group purchase. This article from the perspective of consumers, based on customer perception theory, puts forward the hypothesis of the influencing factors of consumers' purchase intention in group purchasing of ecommerce platform, and explores the factors that influence the scene characteristics of consumers' purchases, which helps to deeply understand the behavior of consumers participating in network group buying. Provide theoretical guidance for e-commerce practitioners.

\section{RELATED THEORIES AND ASSUMPTIONS}

\section{A. Related theories and assumptions}

1) Customer perception value theory: Zeitham and Parasuraman propose that customer perceived value is based on the perception of gain and loss, and the overall evaluation of the product's utility by the customer, namely the ratio of perceived benefit to perceived sacrifices [8]. Since online group purchase is a kind of consumption method [9], the benefits and costs of the required products and services will be evaluated during the purchase of products and services by consumers. Therefore, customer perceived value is the basis of consumer buying behavior [10]. S Cai proposed the customer perception model of ecommerce which includes process value and result value [11]. S Forsythe divides customer perceived value into perceived interest and perceivable risk, in which perceived benefit stimulates consumer purchase behavior as a result of purchase [12]. The higher the customer's perceived convenience, the higher the consumer's online transaction propensity and online involvement [13]. Customer perceived value is the most direct motivation for consumers to purchase and affects the entire process of consumer purchase behavior.

This article believes that customer perceived value in group purchasing includes not only the acquired value of the purchased product itself, but also the utility brought by the entire consumption process. Therefore, based on the perceived value of the customer, the purchase behavior of the group purchasing is studied. Obviously, perceptual benefit is the product result value compared with daily individual purchase under the group purchase scenario. Perceived convenience is the process value of perceiving group purchase. It can be seen that customer perceptual value theory can better explain consumers' purchase in group purchase. Influencing factors of behavior.

2) Time interpretation level theory: Time is one of the main factors affecting individual choice and decisionmaking. The field of decision-making and economics has long found that with the passage of time or delay, people's subjective value of the object will be discounted, giving more value to the recent object. At the same time, this discount rate will vary according to the object (such as money, effort, etc.), and even the phenomenon of value reversal $[14 \sim 15] . \quad$ At the same time, the Temporal construal level theory (TCLT) points out that people use an abstract mental model to characterize near future events using a specific psychological model, Low-level construal. As the distance of the behavior changes, people's psychological interpretation of future behavior is different. The smaller the distance in time, the easier it is for the behavior to be interpreted according to secondary characteristics [16]. This change in time distance is actually a change in the time level of the event, that is, the time at which the event occurred.

Because time plays an important role in the interpretation of events, it should also play a role in the purchase behavior of online group buying customers. Therefore, in this article, the duration of group opening will be taken as the research object that affects the customer's buying behavior.

3) Limited decision theory: Numerous studies by economists and psychologists have shown that the theory of expected utility based on the "rational person" hypothesis does not correspond to the actual purchase decision-making behavior of consumers. The most obvious is that it cannot explain the Allais paradox (Allais, 1952) and the Ellsberg paradox (Ellsberg, 1961). In the actual application process, the consumer's needs, emotions, cognition, motivation, personality structure and other psychological factors and cultural backgrounds, decision-making situations, etc., all have a significant impact on the actual decision-making process, and will make the decision-making process deviate from the rational rules. Among the most influential are the professors of the Nobel Prize in Economics Simon (1955) who proposed the theory of "limited rationality." The theory holds that consumers' purchasing decisions will be subject to a series of internal and external factors, so consumers' purchasing decisions cannot be completely "rational" and they cannot follow the principle of "maximization of utility" in decision-making. Only relatively satisfactory decisions need to be made. [17]

Combining limited decision theory with herd mentality, group buying desire is the behavior of other customers and will have an impact on customers. Therefore, this article believes that the number of people buying has a certain relationship with the final group purchase sales, that is, the completion of the customer's purchase behavior. Explore. 


\section{B. Research Hypothesis}

1) Discount rate: The rapid development of ecommerce has made online shopping a part of life. Online shopping has its unique advantages, among which price is one of its main advantages [18]. The majority of consumers in China are price-sensitive consumers, focusing on price levels and preferences [19]. And consumer transactions are conducted online. Discounts and other factors are key factors that stimulate consumers to shop online [20]. The discount rate is a reflection of the original price of the product compared to the price of the group purchase promotion, which can give consumers higher purchase willingness and perceived value.

The drop in the price caused by the discount rate will increase the consumer's perceived low price, thereby stimulating their purchasing behavior. The higher the discount rate, the more profitable the consumer will be, and the more obvious the buying behavior will be. Thus, the following assumptions are made:

H1: Discount rate has a significant positive impact on ecommerce platform consumer buying behavior

2) Group purchase time: The time of group purchase is the limited time for this group purchase. The length of group purchase will affect the purchase behavior of consumers. The limited duration people can use is also known as time pressure [21]. The longer the group purchase time, the less time pressure consumers feel and the more positive emotions consumers will have, and the more time consumers have to choose [22], The greater the pressure of time, the more aggressive the consumer's Internet buying propensity is to increase [23]. Based on the temporal interpretation hierarchy theory, the mechanism of the subjective evaluation of events changing over time is discussed, which provides a basis for human rational decision-making, and the use of specific psychological models for the representation of future events of near time, ie low-level interpretation. When consumers make purchase decisions, the greater the time pressure, the more consumers focus on the objective factors of the product.

The length of group purchase will influence consumers' purchase decision. Due to the increase of time pressure, the depth of information search is gradually weakening, and the information search mode gradually tends to be based on attribute processing [24]. Consumers are more likely to pay attention to factors such as convenience and low price in group purchase and promote consumer purchase behavior. Thus, this study yields the following assumptions:

H2: Group purchasing time has a significant negative impact on e-commerce platform consumer buying behavior

3) Want to buy people: The number of people to buy is a reflection of the consumer group's idea of the purchase of the product. The consumer's belief that the product is positive or negative is an important basis for predicting whether or not the consumer will have a product in the future. Consumers can understand the purchase ideas of other consumers through the indicators of the number of goods to buy. Other consumers' buying ideas will affect the consumer's purchase intention [25]. Based on the limited decision theory and the herd mentality, consumers can understand the purchase ideas of other consumers through the buy-to-buy numbers of commodities. The idea of other consumers' purchases largely influences the consumer's purchase intention [26]. The buying idea is the key to determining consumption. The increase in the number of people who want to buy will prompt consumers to have positive buying ideas. Thus, the following assumptions are made:

H3: The number of purchasers has a significant positive effect on the purchase behavior of e-commerce platform consumers

\section{DATA COLLECTION AND GEPHI ViSUAL ANALYSIS}

\section{A. Data Collection and Preprocessing}

The data of this experiment is from a well-known largescale shopping platform in China. It is the largest online shopping retail e-commerce transaction platform in China. It provides comprehensive information on product group purchase, including the name, store name, sales volume and promotion of the group purchase product. Price, original price, open group time, end time, want to buy time and other information, so choose Taobao to collect data. This article conducts online data collection through a Python-based crawler program. This article finds that in the grouppurchased products, the group purchase of apparel products accounts for a large proportion of group purchases in all categories. In order to be more representative of the research results, this article selected clothing products for data collection. After removing some of the missing data, a total of 35,402 data were obtained.

After processing the data of the factors that influence the purchasing characteristics of the consumer's purchase behavior in the e-commerce platform, the data is generated into a .CSV file containing the data nodes and the connection relationship and imported into the GEPHI software. The software will automatically merge the same nodes and calculate the number of data node connections. The independent variables (group purchase time, number of people to buy, discount) and sales volume are processed into GEPHI, and the Fruchterman Reingold layout mode is selected to rearrange the data.

\section{B. Network Density Analysis}

Gephi is open source cross-platform jvm-based complex network analysis software, which is mainly used for interactive visualization and exploration of various networks and complex systems, dynamic and hierarchical map open source tools, exploratory data analysis, link analysis, Social network analysis is a tool for visualizing information data.

The network density reflects the integrity of the network. If there is an edge connection between any node in a 
complex relational network, then the density of the network is 1 , and the reachability of this network is the best. If the network density is greater, small, then the worse the integrity of the network. In the Gephi visualization analysis in this study, due to the large amount of data, stratified sampling was selected for data verification in "Table I".

TABLE I. DATA TEST RESUlts

\begin{tabular}{l|l}
\hline & Graph Density Report \\
\hline The group purchase time & 1.600 \\
\hline Country & 0.723 \\
\hline Discount & 0.917 \\
\hline
\end{tabular}

Directed graph network density calculation: number of edges/ (number of nodes*number of nodes-number of nodes)

Explanation: (number of nodes * number of nodes number of nodes) This calculates the maximum number of connected edges (not including itself). Dividing the actual number of edges by the maximum possible number of edges is the density. The larger the result, the more the nodes in the graph are connected. Closer

It is easy to see that the network density is close to and greater than 1 in the duration of group purchases, number of purchases, and discount rate. Among them, the longest influence factor of the purchase duration is the highest, and it can be concluded that the quantity of the group purchase products is most closely related to the group purchase time. The poor degree of association of the number of people to buy has the least impact on the sales volume of group purchase products.

\section{Drawing a Map}

Using the "Fruchterman Reingold" algorithm plug-in to create a map of the factors affecting group sales in "Fig. 1", "Fig. 2" and "Fig. 3", we can see that the relationship between the research subjects is clear and the core points are clear. In the group purchase time, the 47-hour group opening time is most important for sales in "Fig. 1"; In the factors affecting the group purchase products, the number of people wanting to buy is more closely linked in "Fig. 2"; due to the large sales volume, the 1000-2000 sales volume is regarded as 1 , and the 2000-3000 sales volume is regarded as 2, and so on. This can be found under the influence of discounts, the sales discount of 2000-3000 is more significant, followed by $1000-2000$ and $0-1000,4000-5000$ times in "Fig. 3";

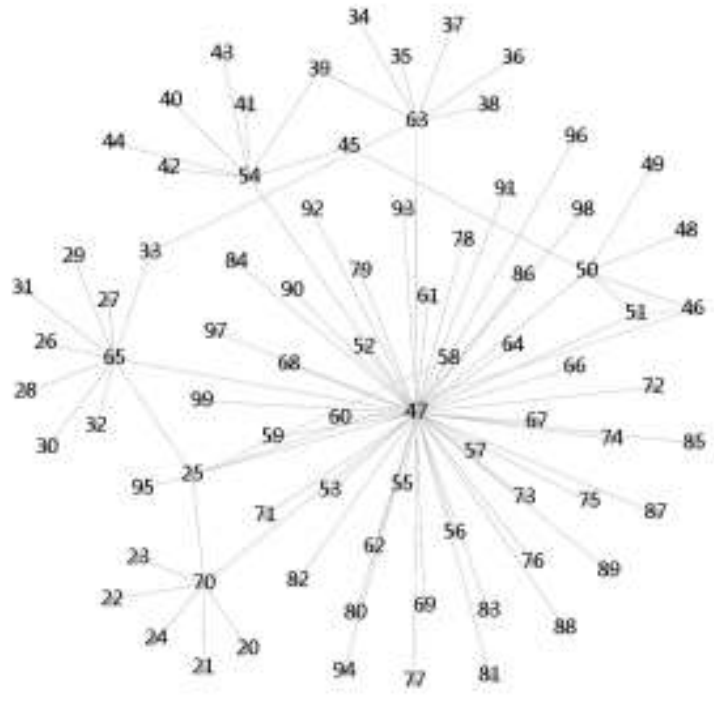

Fig. 1. The map of the factors affecting group sales in the group purchase time.

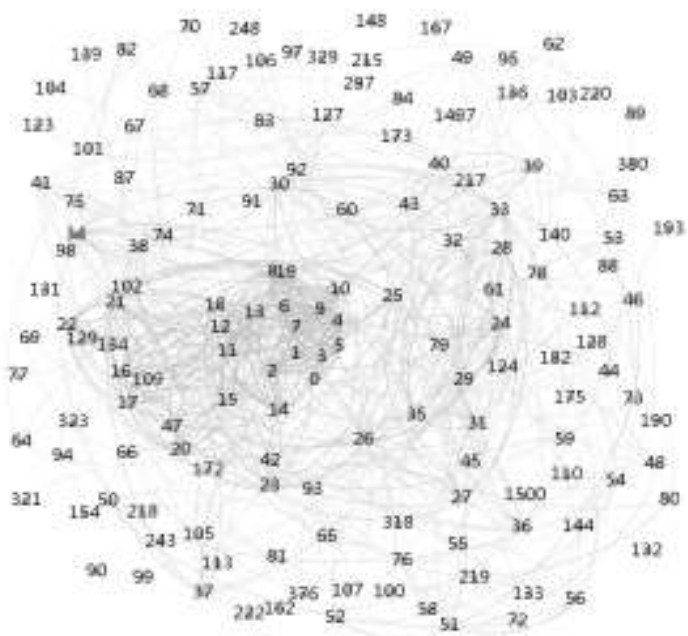

Fig. 2. The map of the factors the factors affecting the group purchase products. 


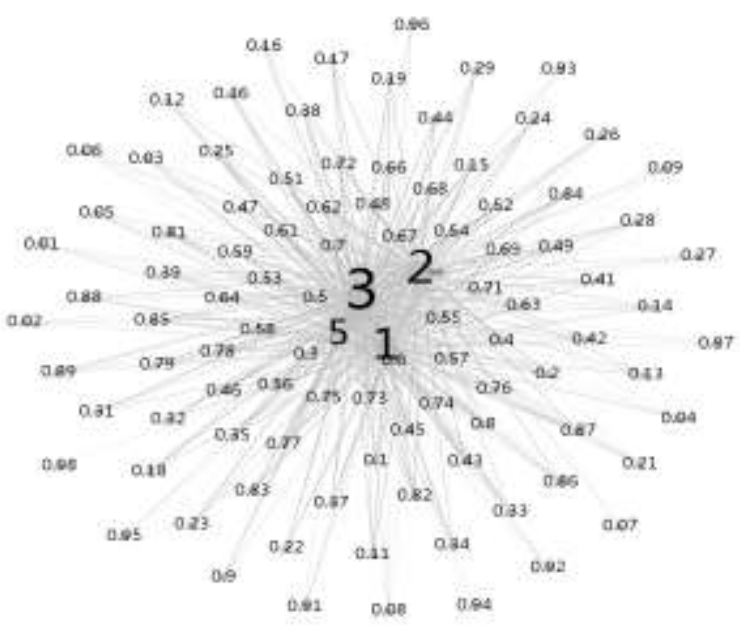

Fig. 3. The sales discount under the influence of discounts.

Using GEPHI analysis to study the impact of contextual factors on consumer purchasing behavior, and using its powerful visual calculations to visualize and correlate the relevance of the hypotheses, it can be deduced that the discount rate, the number of people wanting to buy, the duration of group purchase and the sales volume are relatively close. The correlation relationship starts from this correlation to further empirically analyze the degree of its specific impact.

\section{Multivariate LOGISTIC REGRESSION ANALYSIS}

\section{A. Variable Description}

After a preliminary analysis of the correlation between variables through Gephi, there is a correlation between discounts, number of purchases, duration of group purchase and sales volume. In order to further get the specific impact between variables, the paper establishes a linear regression. The model was used to test the relationship between variables, and multiple linear regression analysis was performed on 35402 data by SPSS 21.0. First, descriptive statistical analysis and correlation analysis between variables were used to obtain the characteristics of the data and regression analysis was possible in "Table II", "Table III" and "Table IV".

TABLE II. DATA CHARACTERISTICS

\begin{tabular}{lllllll}
\hline \multicolumn{1}{c}{ variable } & \multicolumn{1}{c}{ Observations } & \multicolumn{1}{c}{ average value } & \multicolumn{1}{c}{ Standard deviation } & \multicolumn{1}{c}{ Min } & \multicolumn{1}{c}{ Maximum } & VIF \\
\hline Ln (sales) & 35402 & 77.14 & 533.21 & 1 & 44777 & -- \\
Ln (original price) & 35402 & 278.64 & 182.41 & 16 & 4399 & 1.10 \\
Ln (discount rate) & 35402 & 0.56 & 23.42 & 0.01 & 1 & 1.04 \\
Ln (group purchase time) & 35402 & 76.92 & 0.68 & 22 & 122 & 1.12 \\
Ln (number of people wanting to buy) & 35402 & 37.94 & 265.63 & 0 & 14722 & 1.05 \\
\hline
\end{tabular}

TABLE III. CORRELATION TEST OF VARIABLES

\begin{tabular}{|c|c|c|c|c|c|}
\hline variable & Sales volume & Original price & Discount Rate & Group purchase time & Want to buy people \\
\hline Sales volume & $1.000^{*}$ & & & & \\
\hline Original price & $-.058 *$ & $1.000 *$ & & & \\
\hline Discount Rate & $.059 *$ & $.184 *$ & $1.000 *$ & & . \\
\hline Group purchase time & $-.247 *$ & $.233^{*}$ & $-.056^{*}$ & $1.000 *$ & \\
\hline Want to buy people & $.663 *$ & -.034 & $.068 *$ & $-.226^{*}$ & $1.000 *$ \\
\hline
\end{tabular}

TABLE IV. VARIABLE DESCRIPTION

\begin{tabular}{|c|c|c|c|}
\hline $\begin{array}{l}\text { Variable } \\
\text { category }\end{array}$ & Variable name & Variable description & measurement method \\
\hline $\begin{array}{l}\text { Dependent } \\
\text { variable }\end{array}$ & Sales volume & Consumer purchases & Online purchase quantity \\
\hline $\begin{array}{l}\text { Independent } \\
\text { variable }\end{array}$ & Discount Rate & The ratio of goods to their original price & $\begin{array}{l}\text { The difference divided by the } \\
\text { original price }\end{array}$ \\
\hline & Want to buy people & To buy before the start of group purchase & Want to buy people \\
\hline & Group purchase time & The period from the start of group purchase to the end of group purchase & End time minus group opening time \\
\hline Control variable & Original price & The total price of the product & The total price of the product \\
\hline
\end{tabular}

\section{B. Model Estimation}

In the context feature of e-commerce platform buy-in, consumers' purchase intention is often affected by multiple factors that will reflect the group-purchasing service products. The discount rate, number of people wanting to buy, and group purchase time are used as predictors of consumer buying behavior. The dependent variable is used. The final sales volume of group purchases indicated that multiple linear regression models were used to test the effect of discount rate, number of buyers, and group purchase time on this group purchase. In order to avoid the multicollinearity between the data and facilitate the analysis at the same time, all the data are calculated in logarithmic incorporation model.

In this formula, the sales volume represents the final volume of the group purchase, the original price represents the price of the product before the group purchase, the group purchase duration indicates the total length of time from the start of group purchase to the end of the group purchase, and the number of people wanting to purchase indicates the total number of people who have a willingness to purchase before the group opens. 


\section{Regression Results}

"Table V" reports the results of a multiple regression model. The F-test of the model $(7230.9, \mathrm{P}<0.01$.) was significant; while the interaction items were tested, the variables were centralized and the existence of multicollinearity was avoided. The overall R2 value is 0.45 , indicating that the overall interpretation of the outcome variable for the independent variable and the control variable is $45 \%$.

There was a significant positive relationship between the interaction of price and discount rate and the outcome variable (42.286, $\mathrm{P}<0.01)$. The price would increase the positive impact of the increase of discount rate on purchase behavior. Hypothesis 1 was passed. It shows that the price has a positive effect on the relationship between the discount rate and the number of purchasers, and the factor of discount rate plays a significant role in the generation of consumer purchase behavior. For e-commerce platform website group purchase, when discussing price strategy with service providers, we can obtain relative discount rate for products, which makes the products show appropriate economy, and it can generate attractiveness for potential consumers. Increase profit as much as possible. There is a time limit for the duration of group purchase, and the shorter the time from the end of the group purchase, the more consumers notice the appearance of the product. According to Table 5, the length of group purchase is significantly negatively correlated with the number of purchasers $(-2.238 . P<0.01)$, indicating that the e-commerce platform's appropriate shortening of group purchase time can have a certain incentive effect on consumers. The number of people wanting to purchase has a significant positive effect on sales growth, indicating that individual behavior will be affected by the surrounding groups. Finally, the original price of the control variable also has a significant negative effect on consumer purchases, but the impact is not significant. The reason may be that under the specific group purchase scenario, the impact of scenario characteristics is greater than the effect of product characteristics.

TABLE V. EMPIRICAL RESULTS

\begin{tabular}{llll}
\hline variable & B & Standard error & T value \\
\hline (constant) & $189.622 * * *$ & 10.493 & 18.071 \\
Original price & $-.047 * * *$ & .012 & -3.844 \\
Discount Rate & $42.286 * * *$ & 12.805 & 3.302 \\
Group purchase time & $-2.238^{* * *}$ & .095 & -23.537 \\
Want to buy people & $1.283 * * *$ & .008 & 157.659 \\
\hline F value & & $7230.9 * * *$ \\
R2 & 0.45 \\
\hline$* * *$ indicates that the significant level does not exceed $1 \%, * *$ indicates that the significant leve
\end{tabular}

does not exceed 5\%, and * indicates that the significant level does not exceed $10 \%$

\section{CONCLUSION}

Based on the existing research, this article explores the influence of the e-commerce platform group purchase scenario on consumers' purchase intention. Based on the existing research and consumer group purchase behavior issues, it proposes the influencing factors of consumer group purchase behavior. Through Gephi's visual processing, statistical indexes such as discount rate, number of people wanted to buy, duration of group purchase and final product sales, such as graph density, average path, and network diameter, are statistically calculated, and values are observed through the dynamic evolution process and the final view of the data in the experiment. The change of correlation and the formation of higher density laid the foundation for the subsequent significance of empirical research. Then a multivariate linear regression model was established. The empirical study verifies that the characteristics of the discount rate, the number of people wanting to buy, and the duration of group purchase in the e-commerce platform group purchase are all It has a significant impact on consumer purchasing behavior, and it is also a reasonable exploration of e-commerce platform marketing in specific environments. Based on this research result, the author suggests that when conducting group purchase activities, merchants should focus on adjusting the length of the group opening, setting the discount rate, and changing the number of individual products to be bought. On the one hand, the marketing strategy should be formulated accordingly. Timely optimization and adjustment of group purchase activities. However, this article also has some deficiencies, such as the group purchase process also includes other influencing factors, such as the promotion of the group purchase, slogans, etc., these factors will also greatly affect the choice of consumers; all data collection is conducted on the same online shopping platform. You can also choose other ecommerce platforms for research. In addition, the data on group purchases collected this time is limited to the clothing category. You can compare and analyze the remaining product categories to observe how different products influence consumer purchase behavior during group purchase.

\section{REFERENCES}

[1] Mo Yuqing. "2016 (I) China E-Commerce Market Data Monitoring Report" was released [J]. Computer and Networking, 2016, 42(18): 12-14.

[2] Zhang Xiaona. The China Internet Network Information Center released its 41st Statistical Report on the Development of China's Internet. [N]. Democracy and Legal Times, 2018-02-06(004).

[3] Anand K S. Group Buying on the Web: A Comparison of PriceDiscovery Mechanisms[J]. Management Science, 2003, 49(11):15461562.

[4] Huang S, Chen L. Factors influencing the Youth attitudes toward groupbuying websites[C]// International Conference on Service Systems and Service Management. IEEE, 2013: 174-178.

[5] Shiau W L, Luo M M. Factors affecting online group buying intention and satisfaction: A social exchange theory perspective[J]. Computers in Human Behavior, 2012, 28(6):2431-2444.

[6] Erdoğmus I E, Çiçek M. Online Group Buying: What Is There For The Consumers?[J]. Procedia - Social and Behavioral Sciences, 2011, 24(24):308-316.

[7] Chen Y F, Lu H F. We-commerce: Exploring factors influencing online group-buying intention in Taiwan from a conformity perspective[J]. Asian Journal of Social Psychology, 2014, 18(1):6275.

[8] Zeitham $1 \mathrm{~V}$, Parasuraman A , an d Berry L L. Deli vering quality servi ce, balancing cust omer percepti ons and expect ation $\mathrm{s}[\mathrm{M}]$ New York :The Free Press, 1990:30 - 32.

[9] Shen Xiaoping,Cai Wei,Xu Di.An Empirical Study on Consumer Purchase Intention of Group Buying in Service Networks[J].Journal 
of Industrial Engineering and Engineering Management,2016,30(04):160-165.

[10] Chang C, Dibb S. Reviewing and conceptualising customer-perceived value[J]. Marketing Review, 2012, 12(3):1-29.

[11] Cai S, Xu Y. Effects of outcome, process and shopping enjoyment on online consumer behaviour[J]. Electronic Commerce Research \& Applications, 2006, 5(4):272-281.

[12] Forsythe S, Liu C, Shannon D, et al. Development of a scale to measure the perceived benefits and risks of online shopping[J]. Journal of Interactive Marketing, 2010, 20(2):55-75.

[13] Wei Mingxia,Xiao Kaihong.Analysis of Perceived Factors Affecting Online Consumer Behavior of B2C Electronic Commerce[J].Science and Technology Management Research,2006(06):175-179.

[14] TropeY, LibermanN.Temporalconstrual.PsychologicalReview, 2003, 110(3):403 421

[15] TropeY.Theoryinsocialpsychology:seeingtheforestandthetrees.Person ality and SocialPsychologyReview, 2004, 8(2):193 200

[16] Liberman N, Trope Y, Wakslak C J. Construal level theoryand consumer behavior $[\mathrm{J}]$. Journal of Consumer Psychology, 2007, 17: 113-117.

[17] Wu F. Shopping Price Game of Online and Offline[C]// Seventh International Conference on Measuring Technology and Mechatronics Automation. IEEE, 2015:977-980.

[18] Li H, Zhao P, Wang Y, et al. A Qualitative Research of Tuangou: Modes, Characteristics and Roles of the New E-Business Model[C]// International Symposium on Information Engineering and Electronic Commerce. IEEE, 2009:750 - 753.

[19] Singhal M, Rajput S, Saxena S. "Impulse Buying in Case of Online Shopping: Exploring the Underlying Reasons"[C]// Innoserve. 2015.

[20] Guan Lihua,Zhu Xiuli,Sun Lei.Effect of discounted clothing price on internal reference price and perceived value of consumers[J].Journal of Zhejiang Sci-tech University,2011,28(03):362-366.

[21] Ozel F. Time pressure and stress as a factor during emergency egress[J]. Safety Science, 2001, 38(2):95-107.

[22] PeiChun Lin, ZhouHern Lin. Buying impulse triggered by digital media[J]. Service Industries Journal, 2013, 33(9-10):892-908.

[23] Zhao Zhanbo,Du Xiaomeng,Liang Fan,Zhu Xiaoming.Influence of product type and time pressure on impulse buying tendency of consumer networks[J].Journal of Marketing Science, 2015, 11(02): 118-132.

[24] Luo Xiaoxi. The influence of degree of involvement and time pressure on information processing in purchasing decision [D]. Hunan Normal University, 2014.

[25] Jiang Yanmei,Zhao Wenping.Analysis of First-time Online Shopping Decision Model Based on Reference Group Influence[J].Statistics \& Decision,2011(24):85-88.

[26] Qi Haifeng. Inquiry into the behavior of Chinese people's herding behavior-Based on the perspective of control[J].Economics and Management Research,2011(01):24-32. 